\title{
PERSONALIDADE: O PANORAMA NACIONAL SOB O FOCO DAS DEFINIÇÕES INTERNACIONAIS
}

\author{
PERSONALITY: THE NATIONAL PANORAMA FROM THE STANDPOINT OF INTERNATIONAL \\ DEFINITIONS
}

PERSONALIDAD: PANORAMA NACIONAL DESDE EL PUNTO DE VISTA DE LAS DEFINICIONES INTERNACIONALES

\author{
Lucas de Francisco Carvalho* \\ Giselle Pianowski* \\ Ana Maria Reis ${ }^{* * *}$ \\ Rosiane Gonçalves Coelho Silva ${ }^{* * *}$
}

\begin{abstract}
RESUMO
Este estudo tem por objetivo investigar como o construto personalidade tem sido compreendido no Brasil por meio de pesquisadores especialistas na área e com base nas publicações científicas dos últimos anos. Participaram desta pesquisa 11 doutores em Psicologia que responderam a um questionário elaborado pelos autores do estudo, acerca da definição do construto. Além disso, foi realizada uma busca pela base de dados Scientific Eletronic Library Online Brasil (Scielo Brasil), nos anos de 2000 a 2013, com o descritor personalidade. No que se refere aos pontos de convergência pelos especialistas nacionais acerca da definição do construto, verificouse, entre os termos mais frequentes, traços de personalidade, padrão de comportamento e estabilidade. Simultaneamente a isso, por um lado, há um número expressivo de publicações nacionais na área da personalidade, por outro, pouco é publicado tratando-se da definição desse construto. Os trabalhos encontrados são apresentados e discutidos.
\end{abstract}

Palavras-chave: Avaliação psicológica. Traços de personalidade. Diferenças individuais.

Texto recebido em 16 de dezembro de 2013 e aprovado para publicação em 21 de outubro de 2015 .

Docente no Programa de Pós-Graduação Stricto Sensu em Psicologia da Universidade São Francisco (USF), Itatiba-SP. E-mail: lucas.carvalho@usf.edu.br.

** Mestra e doutoranda em Psicologia pelo Programa de Pós-Graduação Stricto Sensu em Psicologia da Universidade São Francisco (USF), Itatiba-SP. Bolsista Capes. E-mail: gisellepianowski@gmail.com.

*** Doutoranda em Psicologia pelo Programa de Pós-Graduação Stricto Sensu em Psicologia da Universidade São Francisco (USF), Itatiba-SP. Bolsista Capes. E-mail: anamariareisdasilva@yahoo.com.br.

${ }^{* * * *}$ Mestranda em Psicologia pelo Programa de Pós-Graduação Stricto Sensu em Psicologia da Universidade São Francisco (USF), Itatiba-SP. E-mail: rosiane.silva6@hotmail.com. Endereço: Universidade São Francisco (USF). Diretoria Acadêmica de PósGraduação. Rua Alexandre Rodrigues Barbosa, 45 - Centro, Itatiba-SP, Brasil. CEP: 13251-900. 


\begin{abstract}
This study aims to investigate how personality has been understood in Brazil by expert researchers in the field and based on scientific publications of recent years. Participated of the research $11 \mathrm{PhDs}$ in psychology who answered a questionnaire developed by the authors of this study about the definition of the construct. Furthermore, a search was performed on the Scientific Electronic Library Online Brasil (SciELO-Brasil) database, including the years 2000 to 2013, with the descriptor personality. With regard to the points of convergence by national experts on the definition of the construct, having found among the most frequent terms, personality traits, behavioral patterns and stability. Firstly, there are a significant number of national publications in the area of personality; on the other hand, little is published dealing with the definition of this construct. The works found are presented and discussed.
\end{abstract}

Keywords: Psychological assessment. Personality traits. Individual differences.

\title{
RESUMEN
}

Este estudio tiene como meta investigar como el constructo personalidad ha sido entendido en Brasil por investigadores expertos en esta área y en base a las publicaciones científicas en los últimos años. Participaron en esta investigación 11 doctores en Psicología quienes respondieron un cuestionario, elaborado por los autores del estudio, acerca de la definición del constructo. Además, se realizó una búsqueda en la base de datos Scientific Eletronic Library Online Brasil (SciELO-Brasil), en los años 2000 a 20013, con el descriptor personalidad. Con respecto a los puntos de convergencia de los expertos nacionales sobre la definición del constructo, se encontró entre los términos más frecuentes, rasgos de personalidad, patrones de comportamiento y estabilidad. Simultáneamente a eso, por un lado, hay un número significativo de publicaciones nacionales en el área de la personalidad y, por otra parte, se ha publicado poco sobre la definición de este constructo. Las obras encontradas son presentadas y discutidas.

Palabras clave: Evaluación psicológica. Rasgos de personalidad. Diferencias individuales.

\section{INTRODUÇÃO}

Oor uma rápida busca em bases de dados internacionais, realizada em outubro de 2013, verifica-se, nos últimos anos, um crescente investimento em publicações voltadas para o tema personalidade, ultrapassando $100 \mathrm{mil}$ publicações com a temática nos últimos 14 anos. Por exemplo, na base de dados 
Science Direct, com a palavra-chave personality, foram encontrados 110.648 artigos, com número aproximado entre 4 e 5 mil artigos anuais do ano 2000 até 2004, passando para 6 a 9 mil nos anos de 2005 a 2009. Nos anos que se seguiram, as publicações têm sido superiores a 10 mil artigos anuais, direcionados ao estudo da personalidade. Já no Brasil, essa preocupação parece não ser tão evidente. Pela base de dados Scielo, o resultado de publicaçóes com o termo "personalidade" é de 424 artigos nos últimos 14 anos. A observação desses dados deixa evidente o contraste existente entre a produção científica e possivelmente a preocupação acerca da compreensão do construto personalidade. Este estudo encontra-se nesse ínterim, buscando investigar qual a compreensão atual da personalidade no meio científico nacional. De maneira mais ampla, assim como estudos publicados previamente (Mendes, Nakano, Silva, \& Sampaio, 2013; Noronha, 1999; Noronha, Primi, \& Alchieri, 2005; Padilha, Noronha, \& Fagan, 2007), esta pesquisa visa a investigar como está o conhecimento especializado e científico no Brasil em uma temática específica da Psicologia.

$\mathrm{Na}$ Psicologia, o estudo da personalidade começou a ser expressivamente estruturado na década de 1930, por meio das proposições de Gordon Allport, sendo que seu livro Personality: a psychological interpretation (Allport, 1937) oficializou o marco inicial do estudo da personalidade na ciência psicológica. Allport perseguiu dois objetivos aparentemente contraditórios na tentativa de definir e sistematizar o construto no campo da Psicologia. O teórico tentou preservar uma concepção da personalidade como uma essência espiritual única, a qual não pode ser completamente mensurada por métodos científicos, ao mesmo tempo em que adotou uma compreensão behaviorista de traços, em que sistemas de hábitos e medidas seriam componentes básicos da personalidade (Nicholson, 2003).

A partir dos estudos de Allport, psicólogos acadêmicos começaram a desenvolver estudos científicos da personalidade, o que culminou no surgimento de distintas abordagens para compreensão do construto, como a dos traços, a humanista e a cognitiva. Desde então, a diversidade de abordagens teóricas e metodológicas vem contribuindo para o aprimoramento desse campo de estudo, entretanto suas controvérsias têm persistido ao longo da história da Psicologia da personalidade até os dias atuais (John, Robins, \& Pervin, 2010).

Os estudos caminharam favorecendo a conceptualização da personalidade. Para Allport (1937), a personalidade define-se como uma "organização dinâmica, dentro do indivíduo, dos sistemas psicofísicos, que determina seu ajuste único ao ambiente" (p. 48). Para ele, essa organização dinâmica está ligada aos traços de personalidade, compreendidos como "estruturas neuropsíquicas com a capacidade de incorporar diversos estímulos funcionalmente equivalentes 
e para iniciar e guiar equivalentes (significantemente consistente) formas de comportamento adaptativo e expressivo" (Allport, 1937, p. 347).

Ao lado disso, Cattell também baseou suas produções na área da personalidade no estudo dos traços, sendo que seus trabalhos representam uma importante tentativa de organização dos achados de estudos fatoriais analíticos da personalidade (Hall, Lindsey, \& Campbell, 2000, p 246). Para Cattell (1965), a personalidade é um conjunto de traços que predispõe o indivíduo a agir de determinada forma, nas mais diversas situações. Compartilhando de definições semelhantes às de Allport, Cattell define o traço de personalidade como uma estrutura mental, ou melhor, como uma inferência feita com base no comportamento observado para explicar a regularidade ou a consistência desse comportamento (Hall et al., 2000).

A teoria dos traços persiste atualmente, sendo que o conceito de traço tem um estatuto privilegiado entre os pesquisadores da personalidade (McCrae \& Costa Junior, 1997), inclusive como base para modelos experimentais com expressividade na literatura atual, focando nas bases neurobiológicas desse construto (Corr, 2008). Além disso, de acordo com McCrae e Costa Junior (2003), o que mais se aproxima de um consenso encontrado entre os pesquisadores da personalidade é a tentativa de organizar uma explicação psicológica do funcionamento da pessoa como um todo.

Com base nos modelos iniciais dos traços, originados por Allport, Cattell e outros teóricos, e como tentativa de organizar os traços em várias dimensões da personalidade, surgiu o modelo dos "cinco grande fatores" (CGF), caracterizado por cinco dimensôes amplas da personalidade, as quais se referem a um modelo que pode ser aplicado a indivíduos provenientes de qualquer cultura (McCrae \& Costa Junior, 1997). Trata-se de uma das principais propostas para compreensão da personalidade, que aporta o conceito de traços, já que tem ampla aceitação no meio científico (Goldberg, 1993). Para Rothbart, Ahadi e Evans (2000), há uma concordância geral entre pesquisadores sobre um grupo de construtos de ordem superior para traços de personalidade em adultos. É interessante notar que a literatura internacional, tratando do construto personalidade, aproxima-se de um consenso ao concordar que a personalidade é composta por pelo menos cinco dimensões amplas e a que se referem essas dimensões. Não obstante, a maior parte da literatura tratando do CGF demonstra pouca preocupação, se alguma, com uma definição para a personalidade.

Apesar disso, McAdams e Pals (2006), como tentativa de fornecer uma base conceitual para o CGF, descrevem a personalidade como uma 
Variação única do indivíduo nos moldes evolutivos gerais para a natureza humana, expresso como um padrão de desenvolvimento de traços disposicionais, adaptações características e narrativas de vida autodefinidoras complexas e diferencialmente situadas no contexto cultural e social (p. 204).

Complementando essa definição e corroborando a proposta clássica de Allport (1961), McCrae e Costa Junior (2003) apresentam uma compreensão dos traços de personalidade como características psicológicas estáveis, capazes de definir, em grande parte, como as pessoas experimentam o mundo e quais os impactos que essa forma de experimentar o mundo pode ocasionar em seu contexto.

Além das combinações individuais de traços, McCrae e Costa Junior (2003) enfatizam a estabilidade como ponto-chave na definição e entendimento do que é a personalidade, o que, de certa forma, já havia sido argumentado por Allport (1937). Em consonância, pesquisas sugerem a estabilidade de características da personalidade ao longo do tempo, atribuída em parte a uma base psicobiológica, possibilitando algum sucesso na previsão de tendências comportamentais (Wiggins, 2003). Contudo a estabilidade dos traços de personalidade não é consensual e é discutida na literatura (Mischel, 1968; Roberts, 2009).

Em suma, podem ser observados alguns pontos de maior convergência na definição da personalidade na literatura (Millon \& Davis, 1996; Millon, 2011). $\mathrm{O}$ construto

a) corresponde a um padrão de funcionamento individual; está relacionado (b) a uma combinação de traços de personalidade específicos; apresenta

b) uma relativa estabilidade de resposta ao meio, baseada no padrão de funcionamento; e

c) uma estruturação com base em cinco agrupamentos amplos compostos por traços. Para Millon e Davis (1996), a personalidade se refere a padrōes de funcionamento psicológico, mais ou menos adaptativos (isto é, eficazes), apresentados recorrente e sistematicamente pelos indivíduos diante das demandas do cotidiano.

Apesar da consistência acerca dos pontos relacionados ao conceito de personalidade, a literatura internacional é vasta em propostas que diferem em distintas proporçōes (Millon \& Davis, 1996; John et al., 2010). Diferente, especificamente no Brasil, não foram encontradas propostas para compreensão da personalidade originárias no País, mas sim os estudos realizados se baseiam nos modelos internacionais. Diante desse cenário, partindo de uma breve explanação 
do panorama internacional sobre a definição da personalidade, esta pesquisa objetivou investigar como o construto personalidade tem sido compreendido no Brasil por pesquisadores especialistas na área e com base nas publicações científicas dos últimos anos.

\section{MÉTODO}

De acordo com o escopo deste estudo, o método foi dividido em duas etapas. A etapa 1 corresponde aos procedimentos utilizados para analisar a compreensão da personalidade por especialistas; e a etapa 2 voltada para uma revisão de literatura nacional a respeito do construto.

\subsection{Etapa 1}

\subsubsection{Participantes}

Foram convidados 32 profissionais, sendo 12 da Região Sudeste, 9 da Sul, 4 da Centro-Oeste, 6 da Nordeste e 1 da Norte, via correio eletrônico, incluindo explicaçôes sobre a pesquisa, contato dos autores, questionário a ser respondido e solicitação de prazo de devolução. Dos profissionais convidados, participaram desta pesquisa 11 doutores em Psicologia de diferentes regiões do País, com atividade profissional diretamente relacionada ao estudo do construto personalidade, com, no mínimo três anos de experiência/estudo, com o tema.

\subsubsection{Instrumentos}

Para o estudo, foi elaborado um questionário pelos autores, com duas partes distintas. A primeira, direcionada para a identificação dos especialistas; e a segunda, para a definição do construto personalidade. Na primeira parte do questionário, identificação e caracterização da amostra, o foco se deu no levantamento de dados pessoais e sobre a experiência com a temática em questão, formação, atividades profissionais e filiação atual. A segunda parte, voltada para a definição do construto personalidade, foi composta por 9 questóes, apontadas a seguir, sendo 6 dissertativas sobre a temática, e 3 a serem respondidas em uma escala tipo Likert de 5 pontos, sendo 0 representando "nada" e 4 "totalmente". As questôes foram elaboradas considerando o objetivo da pesquisa, de modo que algumas são mais diretamente relacionadas à temática, definição da personalidade, e outras tratam de assuntos periféricos, mas claramente relacionados ao tema. 
As questões abertas foram:

a) qual a definição de personalidade mais adequada para você como profissional da área?;

b) qual teoria/modelo/proposta de base para a definição? (se possível, insira referência[s] de base);

c) trata-se de uma proposta categórica, dimensional, prototípica, outros?; (4) essa definição engloba aspectos saudáveis e patológicos da personalidade? Caso não, qual dos 2 está englobado?;

d) a teoria/proposta/modelo também é aplicada tanto para aspectos saudáveis quanto patológicos? Se não, para quais aspectos se aplica?; e

e) você utiliza instrumentos de avaliação da personalidade? Se sim, quais e em qual(is) contexto(s)?

As questôes fechadas foram:

a) de 0 a 4, o quanto você acredita/sabe que essa definição é consensual para a Psicologia como ciência?;

b) de 0 a 4, o quanto você acredita/sabe que essa definição é consensual para outros profissionais que estudam personalidade do Brasil?;

c) de 0 a 4, o quanto você considera que essa definição reflete o panorama internacional do estudo da personalidade?

\subsubsection{Procedimentos}

Foi elaborado um questionário, como já descrito, com questôes elaboradas pelos autores, em consenso e baseadas na literatura sobre a temática, gerando um arquivo a ser respondido via e-mail. Em seguida, foi realizado o levantamento dos profissionais a serem convidados, buscando-se representatividade de especialistas nas diferentes regiōes do País, em instituições acadêmicas e que trabalham com o tema personalidade, em pesquisa e, ou, em docência. Para seleção dos especialistas, foram utilizados dois critérios: apresentar publicações (artigos científicos, capítulos de livro ou livros) tratando do construto personalidade e, ou, apresentar pós-formação (mestrado e, ou, doutorado), cuja grande área abarcasse explicitamente o construto personalidade. Para o contato com os especialistas, foi montado um banco com o nome e contato, sendo que inicialmente inseriram-se 
nessa lista aqueles cujos autores deste estudo já tinham conhecimento em relação aos dois critérios utilizados (ainda assim, o Lattes foi acessado para conferência). Depois disso, solicitou-se indicações aos próprios especialistas inicialmente selecionados, na contribuição da busca por profissionais de todas as áreas do Brasil. Considerou-se o banco de especialistas finalizado quando os contatos previamente conhecidos já haviam sido listados e os especialistas acessados não tinham novas indicações. Após o levantamento das informações, os dados foram organizados em planilha eletrônica para avaliação de consensos e discordâncias na definição da personalidade, tanto entre os autores, como diante do panorama internacional.

\subsection{Etapa 2}

\subsubsection{Procedimentos}

Foi realizada uma busca pela base de dados Scientific Eletronic Library Online Brasil (Scielo Brasil), entre os anos 2000 e 2013, com a palavra-chave "personalidade". A escolha da base Scielo Brasil justifica-se pela relevância científica, abrangência da produção nacional e acessibilidade aos manuscritos completos.

Após a busca ampla das produções com a palavra-chave "personalidade", critérios de inclusão e exclusão foram elaborados para a seleção final dos artigos, o que se deu em três fases. $\mathrm{Na}$ fase 1 , foram verificados os títulos e resumos de todos os trabalhos encontrados, selecionando-se os estudos que trataram prioritariamente do construto personalidade. Foram inclusos trabalhos cujo objetivo foi discutir a definição do construto personalidade e, ou, que apresentavam foco explícito no construto personalidade, estudos sobre medidas de avaliação da personalidade e análise de perfis. Optou-se por excluir os trabalhos cujo objetivo visava à relação entre outros construtos e a personalidade, bem como estudos com foco em transtornos da personalidade.

$\mathrm{Na}$ fase 2, foi realizada a leitura completa dos trabalhos elencados na fase 1 , buscando verificar especificamente quais tinham como objetivo discutir a definição do construto personalidade. Observando-se que nenhum preencheu os critérios seletivos da segunda etapa, optou-se por ampliar a verificação dos trabalhos criando-se a fase 3, que consistiu na verificação dos estudos que, apesar de não discutir definições sobre o construto, apresentaram uma ou mais definições para personalidade.

Para análise dos trabalhos que apresentaram a definição do construto (fase 3), foi organizada uma planilha eletrônica que incluiu dados sobre: 

a) região da instituição de filiação dos autores;
b) periódico em que foi publicado;
c) nota/avaliação Qualis Capes do periódico;
d) região do periódico em que foi publicado;
e) ano em que foi publicado;
f) objetivo do estudo;
g) definição(ões) de personalidade apresentadas;
h) teoria/modelo/proposta base para a definição encontrada;
i) tipo de proposta;
j) abrangência da definição/proposta; e
k) instrumentos de avaliação da personalidade utilizados.

Complementarmente, com intuito de explorar o material não incluso na revisão final, foram organizadas planilhas para apresentação de conteúdo e temática também dessas publicações. Para os trabalhos que foram selecionados na etapa 1, que não preencheram os critérios das etapas seguintes, foram levantados dados sobre:

a) região da instituição de filiação dos autores;

b) nota/avaliação Qualis Capes do periódico;

c) região do periódico em que foi publicado;

d) ano em que foi publicado; e

e) objetivo do estudo. O montante de artigos que foram identificados pelo descritor personalidade na Scielo Brasil e que não preencheram os critérios de nenhuma etapa para inclusão nesta revisão foram categorizados de acordo com o objetivo do estudo em:

$\checkmark$ transtornos de personalidade;

$\checkmark$ análise de perfil outro (não personalidade);

$\checkmark$ relação com outras variáveis;

$\checkmark$ não relacionados à saúde mental; e

$\checkmark$ outros. 


\section{RESULTADOS E DISCUSSÃO}

Inicialmente foram analisados os resultados do levantamento com especialistas. Dos participantes, todos exerceram/exercem atividade docente, com tempo de atuação entre 1 e 25 anos $(M=7,54 ; \mathrm{DP}=7,63)$, e estudam/estudaram o construto personalidade por entre 3 e 30 anos $(M=10,27 ; \mathrm{DP}=7,24)$. Dos 11 profissionais, 3 se avaliam como moderadamente especialistas, 4 se consideram muito e 3 totalmente especialistas no estudo da personalidade. Um participante, no entanto, não se considerou especialista na área, porém foi mantido no estudo por apresentar titulação em mestrado e doutorado, incluindo ênfase no construto personalidade, e apresentar publicações na área. Na tabela 1 são apresentadas as estatísticas descritivas da formação e filiação dos profissionais participantes por região.

Tabela 1. Estatísticas descritivas dos profissionais por região

\begin{tabular}{|l|c|c|c|c|}
\hline \multirow{2}{*}{ Região } & \multicolumn{3}{|c|}{ Formação } & \multirow{2}{*}{ Filiação } \\
\cline { 2 - 4 } & Graduação & Mestrado & Doutorado & \\
\hline Sul & 5 & 5 & 4 & 4 \\
\hline Sudeste & 5 & 6 & 7 & 5 \\
\hline Centro-Oeste & 0 & 0 & 0 & 1 \\
\hline Nordeste & 1 & 0 & 0 & 1 \\
\hline Norte & 0 & 0 & 0 & 0 \\
\hline
\end{tabular}

Fonte: elaborado pelos autores.

A seleção de profissionais convidados tinha como objetivo obter uma adequada representatividade nacional, em que todas as regiões pudessem ser contempladas no estudo. Observa-se, no entanto, que os profissionais respondentes ao convite foram prioritariamente formados e filiados a instituiçôes das regiões Sul e Sudeste, sendo apenas um profissional filiado atualmente a uma instituição da Região Nordeste e outro da Centro-Oeste, porém com formação (graduação) e titulação de mestre e doutor na Região Sudeste, e nenhum apresentou formação em algum nível em instituições da Região Norte. Quanto à formação e especialização dos profissionais participantes, verifica-se ainda a predominância de profissionais provenientes de instituições do Sul e Sudeste. Apenas um apresentou sua formação em instituição nordestina, seguida de pós-graduação e filiação atual em instituições das regióes Sudeste e Sul, respectivamente. A formação e filiação dos profissionais predominantemente nas regiōes Sul e Sudeste já era esperada, como já evidenciada em estudos anteriores em Psicologia (Wendt, Lisboa, DeSousa, \& Koller, 2013) e outras áreas da ciência (Mendes, Martelli, Souza, Quirino Filho, \& Martelli Filho, 2010; Romano-Silva et al., 2013). 
Quanto à ênfase da área de pós-graduação dos especialistas, grande parte $(\mathrm{N}=5)$ obteve titulação de mestre e doutor em Psicologia, com ênfase em Avaliação Psicológica, e os demais foram distribuídos em subáreas como Clínica, Psicometria e Educação. Uma parte relevante do grupo $(\mathrm{N}=5)$ apresentou especialização em Psicologia Clínica e observa-se que a maioria dos profissionais $(\mathrm{N}=8)$ apresentou histórico de atuação clínica com período entre 2 e 30 anos $(\mathrm{M}=9,90 ; \mathrm{DP}=9,40)$.

Como acadêmicos, 9 especialistas relataram realizar pesquisas sobre a personalidade, dos quais 8 referiram lecionar disciplinas relacionadas ao construto, como Bases Psicanalíticas da Personalidade, Avaliação Psicológica e Teorias da Personalidade. Como profissionais clínicos, foram identificadas as abordagens Psicanálise (50\%), prioritariamente, seguida da Psicologia Analítica Junguiana (12,5\%), Social-Cognitiva (12,5\%) e Comportamental-Cognitiva $(12,5 \%)$. Cabe ressaltar que um dos profissionais (12,5\%) que relataram prática clínica não destacou uma abordagem. Em relação aos instrumentos de avaliação da personalidade nomeados pelos especialistas como mais utilizados, estão a bateria fatorial da personalidade (BFP), instrumento baseado no CGF e mencionado por 5 especialistas, seguido pelo inventário de personalidade $\mathrm{Neo}-$ Revisado (Neo-PI R) e instrumentos autoexpressivos como o Rorschach, o teste de apercepção temática (TAT) e o teste de Pfister, cada um deles relatados por ao menos 2 profissionais. Ainda, alguns instrumentos foram relatados por somente um profissional, sendo eles, Shedler-Westen assessment procedure (SWAP-200), do inventário de temperamento e caráter, do teste house tree person (HTP) e de marcadores reduzidos da personalidade.

Tomando por base as descrições obtidas pelo tempo de estudo do construto personalidade, o envolvimento em pesquisas e atividades profissionais relacionadas à temática e à autoavaliação quanto especialistas na área, as respostas dadas pelos especialistas ao questionário foram computadas visando a apresentar um panorama do que se tem compreendido sobre personalidade no Brasil. As definiçōes dadas pelos profissionais foram analisadas, e as convergências por pelo menos dois especialistas foram categorizadas quanto aos conteúdos integrantes das conceituações, quanto ao modelo/proposta-base, tipo e abrangência do modelo/proposta citado, o que está apresentado no quadro 1 . 
Quadro 1. Categorização dos componentes das definições de personalidade por especialistas $(\mathrm{N}=11)$

\begin{tabular}{|c|c|c|c|}
\hline & Categoria & Definição & $\mathbf{F}$ \\
\hline \multirow{5}{*}{ Conceituação } & $\begin{array}{l}\text { Conjunto de características/ } \\
\text { traços }\end{array}$ & $\begin{array}{l}\text { Personalidade como construto } \\
\text { que se refere a um conjunto de } \\
\text { características ou de traços. }\end{array}$ & 8 \\
\hline & Modo típico de agir/padrão & $\begin{array}{l}\text { Personalidade como construto } \\
\text { que se refere a modos típicos de } \\
\text { o indivíduo agir, pensar, sentir, } \\
\text { configurando um padrão }\end{array}$ & 6 \\
\hline & Persistentes/estáveis & $\begin{array}{l}\text { Persistência das características } \\
\text { da personalidade ao longo do } \\
\text { tempo, bem como a estabilidade } \\
\text { destas. }\end{array}$ & 6 \\
\hline & Interação/adaptação ambiente & $\begin{array}{l}\text { Características da personalidade } \\
\text { na interação com o ambiente, } \\
\text { visando à adaptação do indivíduo. }\end{array}$ & 5 \\
\hline & Outros construtos & $\begin{array}{l}\text { Construtos que apareceram } \\
\text { dentro da definição, tais } \\
\text { como temperamento, caráter, } \\
\text { identidade. }\end{array}$ & 3 \\
\hline \multirow{3}{*}{ Modelo/Proposta } & Cinco grandes fatores (CGF) & 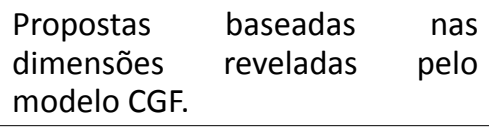 & 4 \\
\hline & Psicanálise/Psicodinâmica & $\begin{array}{l}\text { Propostas baseadas na teoria } \\
\text { psicanalítica e, ou, psicodinâmica. }\end{array}$ & 3 \\
\hline & Outras & $\begin{array}{l}\text { Propostas mencionadas por } \\
\text { apenas um especialista. }\end{array}$ & 4 \\
\hline \multirow[t]{2}{*}{$\begin{array}{l}\text { Tipo do Modelo/ } \\
\text { Proposta }\end{array}$} & Dimensional & $\begin{array}{l}\text { Propostas que compreendem } \\
\text { a personalidade em suas } \\
\text { dimensões. }\end{array}$ & 7 \\
\hline & Híbrida & $\begin{array}{l}\text { Propostas que envolvem mais de } \\
\text { um tipo, comumente categórico } \\
\text { e dimensional. }\end{array}$ & 4 \\
\hline Abrangência & Saudável e patológico & $\begin{array}{l}\text { Propostas que abarcam aspectos } \\
\text { saudáveis e patológicos da } \\
\text { personalidade. }\end{array}$ & 11 \\
\hline
\end{tabular}

Fonte: elaborado pelos autores.

Observa-se que há claro consenso $(72,7 \%)$ em apresentar a personalidade como um conjunto de características, os traços da personalidade. Tal conceituação demonstra afinidade com as definições mais primárias sobre a personalidade como foco do estudo da Psicologia, como Allport (1937) e Cattell (1965), e que tem sido enfatizado atualmente pelo modelo CGF (McCrae \& Costa Junior, 1997; 2003). A partir disso, ressalta-se que o CGF foi o modelo mais citado pelos especialistas $(\mathrm{N}=4)$ como base para a definição e a explicação consideradas mais adequadas sobre a personalidade, e proposta dimensional $(\mathrm{N}=7)$ como a mais consultada como base para a compreensão da personalidade. 
$\mathrm{Na}$ sequência, como pontos mais enfatizados pelos especialistas quanto à conceituação da personalidade, estão o modo típico de agir, o que retrata um padrão de comportamento, e a persistência com que essas características se apresentam na conduta do indivíduo, referindo-se à estabilidade do construto. O padrão de comportamento bem como a estabilidade que o padrão reflete vêm sendo abordados por teóricos, como Allport (1937), ao referir-se a equivalentes formas de comportamento, e Cattell (1965), ao relatar que estaria ligada a uma mesma forma de agir em diferentes situaçôes, o que foi corroborado por Hall et al. (2000). Em sentido semelhante, os teóricos do CGF apontam para a estabilidade dos comportamentos, firmando um padrão de resposta dos indivíduos, ao enfatizar os traços como componentes estáveis da personalidade e responsáveis por definir a forma como as pessoas vivenciam o mundo (McCrae \& Costa Junior, 2003). A questão da estabilidade dos traços de personalidade já foi evidenciada em pesquisas (Wiggins, 2003), porém seus limites são questionados (Mischel, 1968; Roberts, 2009).

Verifica-se, então, pontos de maior convergência por especialistas nacionais em busca da conceituação mais adequada do construto personalidade, a saber, traços de personalidade, padrão de comportamento e estabilidade, elementos citados como consensualmente presentes no levantamento sobre teorias da personalidade realizado por Millon e Davis (1996) e identificados nas definições mais aceitas atualmente, enfatizando-se o CGF (McCrae \& Costa Junior, 2003). Porém outras categorias foram evidenciadas nas descrições dos especialistas, a interação/adaptação ao ambiente, e outros construtos. No que se refere a essas categorias, a personalidade foi abordada como mediadora da adaptação, o que já havia sido englobado por Allport (1937) e McAdams e Pals (2006), ao designarem os comportamentos como adaptativos. Ainda, construtos relacionados à personalidade, como temperamento, caráter e identidade, apareceram como integrantes da definição do construto personalidade. A confusão ou mesmo fusão entre personalidade e determinados construtos (tipicamente, temperamento e caráter) já foi reportada anteriormente na literatura. Temperamento se refere a componentes biológicos atuantes no direcionamento do comportamento humano, enquanto o caráter traz uma conotação moral, relacionada ao convívio e ajustamento dos comportamentos à sociedade (Millon, 2011). Ademais, alguns outros elementos foram mencionados por apenas um especialista: características da personalidade como marcantes ao indivíduo e sinalizadoras de sua singularidade; a personalidade está em um continuum e refere-se a um sistema dinâmico. 
Observando-se a indicação dos especialistas para quais modelos/propostas embasaram suas definiçôes, nota-se que, apesar da predominância do modelo CGF (N=4), o que, de acordo com McCrae e Costa Junior (2003), apresentase como uma proposta adequada para compreensão da personalidade, houve uma ênfase em teorias psicanalíticas e, ou, psicodinâmicas $(\mathrm{N}=3)$, apontando para uma possível tendência nacional para uma abordagem específica mais do que a integração entre abordagens. A preferência por uma abordagem específica foi relatada anteriormente na literatura por McAdams e Pals (2006), o que é corroborado no presente estudo. Além disso, observa-se que parte dos especialistas $(\mathrm{N}=4)$ apresentaram modelos/propostas para conceituação e explicação da personalidade que não se repetiram na amostra: a teoria de organização da personalidade, o modelo circumplexo interpessoal, o modelo psicobiológico de temperamento e Caráter, o modelo do Kernberg, o modelo do Fonagy, o modelo do Westen, a reinforcement sensitivity theory e evolutionary Psychology. Como explicitado por John et al., (2010), é clara a relevância dos diferentes posicionamentos e abordagens para o crescimento da ciência, porém, ainda segundo esses autores, tal diversidade pode favorecer maiores controvérsias quanto ao entendimento do construto, o que foi identificado, nesta pesquisa, nas divergências encontradas quanto à compreensão do construto personalidade no Brasil. As controvérsias são observadas em diferentes aspectos dos modelos (e.g., base conceitual) e nos diversos níveis de aprofundamento (e.g., abrangência). Como exemplo, o modelo predominante na amostra, o CGF, tem como base a teoria dos traços (McCrae \& Costa Junior, 1997), contrastando com modelos circumplexos, cujo foco se dá na sistematicidade do repertório comportamental do indivíduo diante das demandas interpessoais (Kiesler, 1986).

Ao lado disso, como parte da busca por um panorama da compreensão nacional sobre o construto personalidade, foi também realizada uma revisão da literatura, a qual revelou um total de 424 artigos nos últimos 14 anos, com o descritor personalidade, na base de dados Scielo Brasil. Observa-se o saliente contraste entre os resultados encontrados, para o mesmo descritor, em uma base de dados internacional de língua inglesa, que revela número superior a $110 \mathrm{mil}$ artigos publicados sobre a temática no mesmo período. Além de as publicações em língua inglesa incluírem produções oriundas de diversos lugares, com língua inglesa nativa ou não, algumas vezes apresentando participação de estudiosos brasileiros, esses dados revelam uma produção internacional mais de 200 vezes superior ao que se tem investido nacionalmente para a investigação do construto personalidade no que se refere a publicações em artigos científicos.

Foram analisados os resumos dos 424 estudos levantados (categorizados no quadro 2), por meio dos títulos e resumos, e apenas 44 artigos atingiram os 
critérios de inclusão da etapa 1 (isto é, manter somente as publicações tratando prioritariamente do construto personalidade). Desses, 1 artigo foi excluído por se tratar de uma pesquisa realizada em outro país e por autores estrangeiros, mas publicada em revista nacional, o que totalizou 43 artigos elencados nessa etapa. $\mathrm{Na}$ etapa 2, voltada para a identificação dos artigos que apresentaram discussões sobre a definição de personalidade, nenhum artigo foi encontrado, o que gerou a necessidade de organização de novos critérios na busca de alcançar o objetivo de verificar a compreensão que tem sido construída nacionalmente sobre o construto personalidade. Para tanto, foi organizada a etapa 3, buscando abarcar as produções que apresentassem ao menos uma definição sobre personalidade, $\mathrm{o}$ que resultou em 6 artigos.

Quadro 2. Frequência dos artigos revisados na etapa 1 por objetivo

\begin{tabular}{|c|l|c|}
\hline Base de dados & \multicolumn{1}{|c|}{ Categorias de Objetivo } & F \\
\hline \multirow{2}{*}{ Incluídos - Etapa 1 } & Foco no construto personalidade & 3 \\
$(\mathrm{~N}=43)$ & Medidas de avaliação da personalidade & 25 \\
& Análise de perfil da personalidade & 15 \\
\hline & Análise de perfil outros & 58 \\
Excluídos - Etapa 1 & Transtornos da personalidade & 57 \\
$(\mathrm{~N}=381)$ & Relação com outras variáveis & 80 \\
& Não relacionados à saúde mental & 94 \\
& Outros & 92 \\
\hline Total & & 424 \\
\hline
\end{tabular}

Fonte: elaborado pelos autores.

Como observado no quadro 2, para a etapa 1 foram selecionados os artigos que continham em seu título e, ou, resumo foco explícito no construto personalidade $(\mathrm{N}=3)$, sendo estudos teóricos ou empíricos, medidas de avaliação da personalidade $(\mathrm{N}=25)$, que consistia em produções focadas na construção ou verificação das propriedades psicométricas de instrumentos, e análise de perfil da personalidade $(\mathrm{N}=15)$, tratando da análise da personalidade em grupos específicos. Foram excluídos 381 artigos que não preencheram os critérios para seleção na primeira etapa. Esses foram categorizados similarmente às publicações incluídas, sendo as categorias "análise de perfis outros", tratando de estudos com foco no perfil de grupos com base em outros construtos que não a personalidade; "transtornos da personalidade", estudo com foco nesses transtornos; "relação com outras variáveis", sendo estudos com respeito à relação da personalidade e outros construtos; "não relacionados à saúde mental", sendo estudos de outras áreas da Saúde que não a mental (ou mesmo outras áreas que não a de Saúde); 
e "outros", referindo-se à publicações que não se enquadraram nas categorias estabelecidas.

Com o intuito de explorar o material selecionado na etapa 1 , foi realizada uma categorização dos artigos quanto à região da instituição de filiação dos autores, região do periódico em que foi publicado, avaliação Qualis Capes do periódico (nota atribuída em 2013, não no momento da publicação) e ano de publicação. Os 43 artigos foram produzidos por 105 autores, dos quais 64 (61\%) tinham filiação a instituições da Região Sudeste; 16 (15\%), da Região Sul; 9 (8,6\%), da Região Nordeste; e 7 (6,8\%) da Região Centro-Oeste. Ainda, 9 autores $(8,6 \%)$ apresentaram filiação em instituições de outros países, Espanha, Argentina e Estados Unidos, mantidos por estarem vinculados a publicaçôes com autores nacionais. Dos estudos analisados, nenhum autor apresentou filiação em instituições da Região Norte.

Da mesma forma como observado no estudo com os especialistas, a maior parte dos autores eram filiados a instituiçôes das regiōes Sul e Sudeste, com predominância da Sudeste para as publicaçôes, o que permanece linear às origens dos periódicos que veicularam as produções e reflete a realidade nacional já reportada (Wendt, et al., 2013). Do total de 43 publicações, 23 (53,5\%) eram provenientes de periódicos da Região Sudeste; 12 (28\%), da Sul; 7 (16,2\%) da Região Centro-Oeste; e apenas $1(2,3 \%)$ da Região Nordeste. Não foram encontradas publicações em periódicos que correspondiam à Região Norte. No que se refere à avalição Qualis Capes atual para os periódicos identificados, 24 (56\%) apresentaram classificação A2; 12 periódicos (28\%), A1; 4 (9\%), B1; e $3(7 \%)$ periódicos classificados com B2. Quanto ao período de publicação dos artigos, observou-se variância entre os anos 2002 e 2013, com maior número de publicações nos anos de 2012 e 2005, 7 e 6 artigos, respectivamente; e menor número nos anos de 2013 e 2003, com apenas uma publicação em cada ano.

Como não houve artigo que correspondesse ao critério da segunda etapa (discutir definições de personalidade), no quadro 3 são apresentadas as referências dos seis artigos recuperados na etapa 3. Para esta etapa, além dos pontos levantados na categorização dos 43 artigos, foram também categorizadas as definições que apresentaram convergência em pelo menos dois artigos quanto ao conteúdo apresentado, teoria/modelo/proposta-base para a definição encontrada, tipo de proposta (entre categórica, dimensional, prototípica e híbrida), a abrangência da definição/proposta, e instrumentos de avaliação da personalidade utilizados nos estudos. 
Quadro 3. Referência dos artigos recuperados na etapa 3 ( $N=6)$

\begin{tabular}{|l|l|c|}
\hline \multicolumn{1}{|c|}{ Autores } & \multicolumn{1}{|c|}{ Título } & Ano \\
\hline Ayache \& Costa & Alterações da personalidade no lúpus eritematoso sistêmico. & 2005 \\
\hline $\begin{array}{l}\text { Bara Filho, Ribeiro } \\
\text { \& García }\end{array}$ & $\begin{array}{l}\text { Personalidade de atletas brasileiros de alto rendimento: } \\
\text { comparações entre os sexos masculino e feminino e correlação } \\
\text { com nível de performance e tempo de treinamento. }\end{array}$ & 2005 \\
\hline $\begin{array}{l}\text { Carvalho, Nunes, } \\
\text { Primi \& Nunes }\end{array}$ & $\begin{array}{l}\text { Evidências desfavoráveis para avaliação da personalidade com } \\
\text { um instrumento de 10 itens. }\end{array}$ & 2012 \\
\hline Dantas \& Noronha & $\begin{array}{l}\text { Inteligência emocional: validade discriminante entre MSCEIT } \\
\text { e 16 PF. }\end{array}$ & 2006 \\
\hline Martins & A natureza histórico-social da personalidade. & 2004 \\
\hline Gomes \& Golino & Relações Hierárquicas entre os traços amplos do Big Five. & 2012 \\
\hline
\end{tabular}

Fonte: elaborado pelos autores.

Quanto aos objetivos, entre os 6 artigos selecionados, foi identificado apenas 1 como foco explícito no construto personalidade, 3 tratando de medidas de avaliação da personalidade e 2 enquadrados como análise de perfil da personalidade. Os artigos foram produzidos por 14 autores, dos quais 9 (64\%) eram filiados a instituições da Região Sudeste, 2 (14\%) da Região Sul, 2 (14\%) da Região Centro-Oeste; e 1 autor (8,6\%) filiado a uma instituição da Espanha, mantido, já que a publicação também foi realizada por autores brasileiros e a coleta no Brasil. Verifica-se que não houve autoria de pesquisadores filiados a instituições do Norte e Nordeste. Das 6 publicações, 5 artigos (83\%) foram publicados em periódicos da Região Sudeste; e 1 (17\%), da Sul, sendo 3 (50\%) avaliados pela Qualis Capes como A1; 2 (33\%), como B1; e 1 (17\%), como B2. Os artigos foram publicados nos anos de $2004(\mathrm{~N}=1), 2005(\mathrm{~N}=2), 2006(\mathrm{~N}=1)$ e $2012(\mathrm{~N}=2)$.

Diante disso, observa-se que poucos estudos foram direcionados para compreensão com construto personalidade, discutindo, propondo ou criticando a literatura já existente na área, o que pode refletir pouco investimento nacional para um melhor entendimento desse construto. Tal realidade foi evidenciada pela não identificação de publicações empenhadas na discussão teórica acerca da definição do construto e a consequente necessidade de inclusão de uma etapa mais primária no delineamento deste projeto que, mesmo assim, revelou resultado reduzido de publicações. No que se refere à representatividade desse panorama na realidade brasileira, sinaliza-se um maior foco dos estudos sobre a personalidade por pesquisadores vinculados a instituições das regiōes Sul e Sudeste, correspondentes aos achados dos especialistas, o que pode ser reflexo de discrepâncias no incentivo e investimento no estudo da personalidade nas diferentes regiōes. O mesmo tem sido revelado quanto aos periódicos de publicação, sendo exclusivamente provenientes das regiōes Sul e Sudeste. 
Cabe salientar que o número pequeno de publicações nacionais discutindo especificamente a definição do construto personalidade, apesar de não ideal, reflete o panorama internacional, que também é escasso nesse âmbito.

No que se refere aos instrumentos de avaliação da personalidade usados nos estudos levantados, foram encontrados quatro instrumentos utilizados em quatro artigos, a saber, o inventário de características de personalidade, o inventário de personalidade de Freiburg (FPI-R), o questionário fatorial da personalidade (16-PF) e o Ten-Item personality inventory (TIPI). Na tabela 4, a seguir, estão apresentadas as categorizaçóes quanto ao conteúdo das definiçóes, quanto ao modelo/proposta-base, tipo e abrangência do modelo/proposta citado.

Quadro 4. Categorização dos componentes das definições de personalidade pela revisão literária $(\mathrm{N}=6)$

\begin{tabular}{|c|c|c|c|}
\hline & Categoria & Definição & $\mathbf{F}$ \\
\hline \multirow{6}{*}{ Conceituação } & $\begin{array}{l}\text { Conjunto de características/ } \\
\text { traços }\end{array}$ & $\begin{array}{l}\text { Personalidade como construto que se } \\
\text { refere a um conjunto de características } \\
\text { ou de traços. }\end{array}$ & 5 \\
\hline & Modo típico de agir/Padrão & $\begin{array}{l}\text { Personalidade como construto que se } \\
\text { refere a modos típicos do indivíduo agir, } \\
\text { pensar, sentir, configurando um padrão. }\end{array}$ & 2 \\
\hline & Persistentes/Estáveis & $\begin{array}{l}\text { Persistência das características da } \\
\text { personalidade ao longo do tempo, bem } \\
\text { como a estabilidade destas. }\end{array}$ & 2 \\
\hline & $\begin{array}{l}\text { Interação/Adaptação } \\
\text { Ambiente }\end{array}$ & $\begin{array}{l}\text { Características da personalidade na } \\
\text { interação com o ambiente, visando à } \\
\text { adaptação do indivíduo. }\end{array}$ & 2 \\
\hline & Sistema dinâmico & $\begin{array}{l}\text { Componentes da personalidade } \\
\text { apresentam funcionamento dinâmico } \\
\text { entre si. }\end{array}$ & 2 \\
\hline & Outros construtos & $\begin{array}{l}\text { Construtos que apareceram dentro da } \\
\text { definição, tais como temperamento, } \\
\text { caráter, identidade. }\end{array}$ & 2 \\
\hline \multirow{2}{*}{$\begin{array}{l}\text { Modelo/ } \\
\text { Proposta }\end{array}$} & Cinco grandes fatores (CGF) & $\begin{array}{l}\text { Propostas baseadas nas dimensões } \\
\text { reveladas pelo modelo CGF. }\end{array}$ & 2 \\
\hline & Outras & $\begin{array}{l}\text { Propostas mencionadas por apenas um } \\
\text { artigo. }\end{array}$ & 4 \\
\hline \multirow{2}{*}{$\begin{array}{l}\text { Tipo do } \\
\text { Modelo/ } \\
\text { Proposta }\end{array}$} & Dimensional & $\begin{array}{l}\text { Propostas que compreendem } \\
\text { personalidade em suas dimensões. }\end{array}$ & 3 \\
\hline & Não identificado & Não mencionado no artigo. & 3 \\
\hline \multirow{3}{*}{ Abrangência } & Saudável e patológico & $\begin{array}{l}\text { Propostas que abarcam aspectos } \\
\text { saudáveis e patológicos da personalidade. }\end{array}$ & 3 \\
\hline & Saudável & $\begin{array}{l}\text { Propostas que abarcam aspectos } \\
\text { saudáveis da personalidade. }\end{array}$ & 1 \\
\hline & Não especificado & Não mencionado no artigo & 2 \\
\hline
\end{tabular}

Fonte: elaborado pelos autores. 
Observa-se que, convergente aos especialistas, foi identificado algo próximo ao consenso $(83,33 \%)$ no que respeita à apresentação da definição do construto ligada aos traços da personalidade, o que sugere abrangência do CGF, que, no entanto, somente foi citado em 2 publicaçóes das 5 que abarcavam os traços como parte da compreensão sobre personalidade. Demonstrando também linearidade com a compreensão dada pelos especialistas, apesar da diminuída concordância, estão a compreensão da personalidade como modos típicos de agir e o foco na estabilidade de suas características, o que se mostra correspondente à grande parte do que a literatura tem abarcado sobre a definição do construto (Millon \& Davis, 1996), e a finalidade adaptativa da personalidade para o indivíduo, também relatada na literatura (Allport, 1937; McAdams \& Pals, 2006). Ainda, foi mencionada a personalidade como um funcionamento dinâmico de seus componentes, o que não foi abarcado pela compreensão dos especialistas, mas aparece sinalizada na definição de Allport (1937) quando trata a personalidade como uma organização dinâmica.

Concordante às menções realizadas pelos especialistas consultados, a literatura revela ênfase na explicação da personalidade sob uma perspectiva dimensional (50\%), o que internacionalmente tem sido ponto de convergência entre pesquisadores (Rothbart et al., 2000), e apresenta-se como a base do modelo CGF, que tem aceitação satisfatória no meio científico (Goldberg, 1993; McAdams \& Pals, 2006). No entanto, apesar de o modelo dimensional ser abarcado em 3 publicações, o mesmo não aconteceu com o CGF, que foi citado em 2 produçôes compartilhando a categoria modelo/proposta-base com a teoria de Cattell, a perspectiva do materialismo histórico e dialético, e uma visão psiquiátrica sobre a personalidade. Vale ressaltar que tanto a definição apresentada com base na teoria de Cattell como a baseada na psiquiatria foram direcionadas à compreensão da personalidade em uma perspectiva de traços, o que, apesar de não mencionado diretamente nos estudos, sinaliza maior aproximação com a proposta dimensional, base do modelo CGF.

Quanto à abrangência das propostas das definições encontradas nos estudos, observa-se que a maioria abarcou o funcionamento saudável e patológico da personalidade. Duas delas não apresentou menção à abrangência e 1 delas, não necessariamente por se tratar da proposta-base, mencionou a personalidade numa perspectiva saudável. Assim, evidenciou-se uma maior ênfase para os especialistas consultados e na literatura levantada para a compreensão da personalidade tratando dos funcionamentos saudável e patológico.

Considerando os pontos apresentados como consensuais na literatura internacional (padrão de funcionamento individual, combinação de traços de personalidade específicos, relativa estabilidade de resposta ao meio e 
estruturação com base em cinco agrupamentos amplos compostos por traços), todos apareceram de maneira mais ou menos frequente neste levantamento realizado com especialistas e nas produções nacionais analisadas, ainda assim, longe de configurar um consenso. O ponto de convergência mais expressivo foi a compreensão da personalidade como combinação de traços de personalidade específicos. Constata-se, historicamente, a apresentação de propostas claras para definição da personalidade (Allport, 1937; Cattell, 1965), porém a continuidade dos trabalhos que atualmente tratam dos traços, grande parte referentes ao modelo CGF, demonstram maior preocupação em replicar a estrutura dimensional encontrada bem como em verificar sua aplicação prática. A reduzida iniciativa dos estudiosos internacionais em fornecer uma base teórica clara e bem definida sobre o construto personalidade, enfatizando-se a elementaridade e relevância da definição de um construto na apreensão deste, pode estar repercutindo nas divergências encontradas na compreensão acerca da personalidade em um âmbito nacional, o que pode ser verificado em estudos futuros. Observa-se, ainda, que não foram identificados investimentos nacionais consistentes direcionados às lacunas teóricas mencionadas. Deve-se somar a isso um dado qualitativo, não ponderado neste estudo, que se refere ao número reduzido de aceite à participação na pesquisa por parte dos especialistas, o que resultou possivelmente em uma pequena representatividade do número total de especialistas brasileiros na área da personalidade.

Além da não responsividade e a baixa produtividade, sinaliza-se concordância, mesmo que diminuta, em alguns aspectos ligados à compreensão da personalidade partindo-se do ponto de vista da definição do construto, que seriam, além dos traços, a personalidade como um padrão de comportamentos e sua estabilidade temporal. Enfatiza-se ainda a diversidade de construções da definição e diversificado embasamento teórico, por parte dos especialistas e da revisão de literatura, e ainda confusões quanto à diferenciação de construtos relacionados, como temperamento e caráter, e a personalidade em si. Tal panorama, mesclado de concordâncias e divergências, compromete o consenso e desenvolvimento científico coeso sobre o construto, sinalizando fragilidades na compreensão da personalidade no Brasil.

\section{CONSIDERAÇÕES FINAIS}

Verificar o que se tem compreendido sobre o construto personalidade em contexto nacional é um desafio que tem limitações metodológicas claras quanto ao acesso integral aos especialistas e ao que tem sido investigado sobre o tema. Apesar disso, a visibilidade buscada pela ciência em prol do avanço e intercâmbio 
científico torna possível a identificação de estudiosos sobre o construto, formados e filiados a instituições acadêmicas nacionais, e das produçôes relacionadas, o que possibilita o delineamento do panorama geral sobre a compreensão atual do construto personalidade no Brasil.

Partindo-se do pressuposto de que a definição do construto consiste em parte elementar na compreensão deste, o presente trabalho focou o levantamento das definições da personalidade utilizadas nacionalmente, diante de um tracejar internacional a respeito da personalidade. Diante disso, observa-se que, tanto por parte dos especialistas como das publicaçóes, a compreensão que se aproxima de um consenso sobre a personalidade engloba, prioritariamente, o entendimento dos traços psicológicos em uma perspectiva dimensional, o que corresponde ao consenso evidenciado entre os pesquisadores da personalidade internacionalmente (McCrae \& Costa Junior, 1997). Nesse sentido, identificase uma tendência nacional à corroboração quanto à pertinência do modelo CGF na busca da compreensão da personalidade.

Aponta-se, no entanto, que a convergência e aceite ao modelo dimensional dos traços é parcial e controverso no Brasil, com base nos achados desta pesquisa. Apesar de a parcela dos especialistas que participaram no estudo ser questionável quanto à representatividade nacional, corroborando a literatura estudada, podese notar uma diversidade de construçôes conceituais para a personalidade, com embasamento em teorias e propostas variadas. Tal variabilidade, apesar de apresentar alguns pontos de convergência quanto a componentes da definição (traços, padrão de comportamento e estabilidade), revela discordâncias e lacunas na compreensão nacional sobre o construto.

Ao lado disso, apesar de internacionalmente observar-se um destaque quanto à estrutura dimensional, com ênfase no CGF, e diminuto investimento teórico na definição e compreensão da personalidade, o panorama brasileiro tem evidenciado um empenho restrito e disperso no acréscimo à ciência na construção do conhecimento sobre o construto, sobretudo no que se refere a seus aspectos mais elementares. Sem subestimar os investimentos de pesquisadores brasileiros, de relevância inquestionável para o momento epistemológico do estudo da personalidade, ressalta-se a necessidade de maior atenção para o construto personalidade no que se refere à sua definição, para além dos estudos de campo que são amplamente encontrados na literatura. 


\section{REFERÊNCIAS}

Allport, G. W. (1937). Personality: a psychological interpretation. New York: Holt. Allport, G. W. (1961). Pattern and growth in personality. New York: Holt.

Ayache, D. C. G. \& Costa, I. P. (2005). Alterações da personalidade no lúpus eritematoso sistêmico. Revista Brasileira de Reumatologia, 45(5), 313-318. Recuperado a partir de http://dx.doi.org/10.1590/S048250042005000500006

Bara Filho, M. G., Ribeiro, L. C. S. \& Garcia, F. G. (2005). Comparação de características da personalidade entre atletas brasileiros de alto rendimento e indivíduos não-atletas. Revista Brasileira de Medicina do Esporte, 11(2), 115120. Recuperado a partir de http://www.scielo.br/pdf/rbme/v11n2/a04v11n2. pdf

Carvalho, L. D. F., Nunes, M. F. O., Primi, R. \& Nunes, C. H. S. S. (2012). Evidências desfavoráveis para avaliação da personalidade com um instrumento de 10 itens. Paidéia, 22(51), 63-71.

Cattell, R. B. (1965). The scientific analysis of personality. Baltimore: Penguin.

Corr, P. J. (2008). The reinforcement sensitivity theory of personality. New York: Cambridge University Press.

Dantas, M. A. \& Noronha, A. P. P. (2006). Inteligência emocional: validade discriminante entre MSCEIT e 16 PF. Paidéia, 16(33), 59-70. Recuperado a partir de http://www.scielo.br/pdf/paideia/v16n33/09.pdf

Goldberg, L. R. (1993). The structure of phenotypic personality traits. American Psychologist, 48(1), 26.

Gomes, C. M. A. \& Golino, H. F. (2012). Relações hierárquicas entre os traços amplos do Big Five. Psicologia: Reflexão e Crítica, 25(3), 445-456. Recuperado a partir de http://www.scielo.br/pdf/prc/v25n3/v25n3a04.pdf

Hall, C. S., Lindsey, G. \& Campbell, J. B. (2000). Teorias da personalidade. (4a ed.). Porto Alegre: Artmed.

John, O. P., Robins, R. W. \& Pervin, L. A. (2010). Handbook of personality: theory and research. New York: Guilford. 
Kiesler, D. J. (1986). The 1982 interpersonal circle: an analysis of DSM-III personality disorders. In T. Millon \& G. L. Klerman (Eds.), Contemporary directions in psychopathology: towards the DSM-IV. (pp. 57-597). New York: Guilford.

Martins, L. M. (2004). A natureza histórico-social da personalidade. Cadernos Cedes, 24(62), 82-99.

McAdams, D. P. \& Pals, J. L. (2006). A new big five: fundamental principles for an integrative science of personality. American Psychologist, 61(3), 204-217.

McCrae, R. R. \& Costa Junior, P. T. (1997). Personality trait structure as a human universal. American Psycologist, 52(5), 509-516.

McCrae, R. R. \& Costa Junior, P. T. (2003). Personality in adulthood: a five-factor theory perspective. New York: Guilford.

Mendes, L. S., Nakano, T. C., Silva, I. B. \& Sampaio, M. H. L. (2013). Conceitos de avaliação psicológica: conhecimento de estudantes e profissionais, Psicologia: Ciência e Profissão, 33(2), 428-445.

Mendes, P. H. C., Martelli, D. R. B., Souza, W. P., Quirino Filho, S. \& Martelli Júnior, H. (2010). Revista Brasileira de Educação Médica, 34(4), 535-541.

Millon, T. (2011). Disorders of personality: introducing a DSM/ICD spectrum from normal to abnormal. New Jersey: Wiley.

Millon, T. \& Davis, R. D. (1996). Disorders of personality. New Jersey: Wiley.

Mischel, W. (1968). Personality and assessment. New York: Wiley.

Nicholson, N. (2003). How to motivate your problem people. Harvard business review, 81(1), 56-65.

Noronha, A. P. P. (1999). Avaliação psicológica segundo psicólogos: usos e problemas com ênfase nos testes. (Tese de Doutorado), Pontifícia Universidade Católica de Campinas, Programa de Pós-Graduação em Psicologia, Campinas.

Noronha, A. P. P., Primi, R. \& Alchieri, J. C. (2005). Instrumentos de avaliação mais conhecidos/utilizados por psicólogos e estudantes de psicologia. Psicologia, Reflexão e Crítica, 18(3), 390-401.

Padilha, S., Noronha, A. P. P. \& Fagan, C. Z. (2007). Instrumentos de avaliação psicológica: uso e parecer de psicólogos. Avaliação Psicológica, 6(1), 69-76. 
Roberts, B. W. (2009). Back to the future: personality and assessment and personality development. Journal of Research Personality, 43(2), 137-145.

Romano-Silva, M. A., Correa, H., Oliveira, M. C. L., Quirino, I. G., Colosimo, E. A., Martelli, D. R., ... Oliveira, E. A. (2013). Perfil e análise da produção científica dos pesquisadores brasileiros em Neurociência Clínica. Revista de Psiquiatria Clinica, 40(2), 53-58.

Rothbart, M. K., Ahadi, S. A. \& Evans D. E. (2000). Temperament and personality: origins and outcomes. Journal of Personality and Social Psychology, $78(1), 122-135$.

Wendt, G. W., Lisboa, C. S. M., DeSousa, D. A. \& Koller, S. H. (2013). Perfil dos bolsistas de produtividade em pesquisa do CNPQ em psicologia. Psicologia: Ciência e Profissão, 33(3), 536-547.

Wiggins, J. S. (2003). Paradigms of personality assessment. New York: Guilford. 